\title{
Use of X-ray fluoroscopy in orthopedic operations: The patient's perspective
}

REVIEW

This article was published in the following Dove Press journal:

Drug, Healthcare and Patient Safety

17 June 2009

Number of times this article has been viewed

\author{
Zain Ul-Abadin' \\ Faisal rauf Khan ${ }^{2}$ \\ Shams Rauf ${ }^{3}$ \\ Nadia Rauf ${ }^{3}$ \\ 'Blackpool Victoria Hospital, \\ Blackpool, UK; ${ }^{2}$ Ysbyty Gwynedd, \\ Bangor, North West Wales, UK; \\ ${ }^{3}$ Gynaecology LRH, Peshawar, Pakistan
}

\begin{abstract}
We collected data from 50 patients who had orthopedic trauma surgery involving X-ray fluoroscopy. All patients were interviewed post-operatively. The aim of the study was to find out what patients thought of orthopedic trauma surgery, the radiation involved, and their concerns post-trauma surgery. Were they given information about the procedures? Did the surgery follow the Department of Health, UK guidelines? That is, consent should be informed, etc. Results showed that most of the patients were unaware of the fact that they were X-rayed during the operation; hence the emphasis on informed consent should be stressed. Most of the patients were unaware about the availability of any protective clothing (lead shield). Even some female patients were unaware of the harmful effects of the radiation on the fetus. Hence, we recommend that more information and education be given to orthopedic trauma patients regarding X-rays.
\end{abstract}

Keywords: X-ray use, orthopedic operations, patients, awareness

\section{Introduction}

We are increasingly living in an information society. With the use of internet and other means of information, patients are more likely to be involved in decision-making then ever before. It is therefore important that clinicians and National Hospital Service (NHS) trusts meet their patient's expectations by providing an environment that is friendly and informative. Modern orthopedics has become increasingly characterized by operative intervention, ${ }^{1}$ especially trauma surgery, where intraoperative fluoroscopy is routinely used. We searched the literature and found that no study has reported the patient's perspective with regard to use of X-rays in their trauma operations. ${ }^{2} \mathrm{We}$ therefore decided to evaluate the patient's perspective on this issue.

The aim of the study was to identify patient's awareness and concerns postorthopedic trauma surgery, and thus to modify our practise to improve the service we provide to our patients.

\section{Material and methods}

\section{Methods}

Only those patients who had trauma surgery were involved. No elective patients were involved. Those patients were excluded who could not comprehend and answer the questions. Confused patients (abbreviated mental score less than 7) were excluded. That satisfies the inclusion and exclusion criterion. All the patients in the study were informed. They were given an option to opt out if they wanted. The questionnaire was unbiased and validated.
Correspondence: Faisal rauf Khan LAT Urology, Eastbourne District General, East Sussex, UK Email f.khan@doctors.org.uk 


\section{Statistical analysis}

The age of the patients was between 13-80 years, and their native language was English. The doctor interviewed patients. Patient queries were answered. The surgical procedures included: Dynamic hip screw, K-wire fixation, manipulation, open reduction, and internal fixation. All patients were interviewed $2-3$ days post-operatively. Patients used a specifically designed questionnaire to ask and answer questions. ${ }^{2}$ The study was performed in two orthopedic wards of a busy district's general hospital. In total, seven questions were asked (Figure 1). The first question was about the general information and understanding the patient had about X-rays. ${ }^{1}$ The next three questions were about information given to them about the X-rays before the operation. The remaining three questions were about X-rays in the pregnant patients.

\section{Results}

Eighty-four patients were involved in the study. Out of these, 13 were confused (based on Abbreviated Mental Score test [AMST]), 12 of them were children, and nine could not be contacted. Of the remaining 50 patients, all were Caucasians, 35 female and 15 male. Generally, the patients were happy with the overall service provided by the hospital.

As regards the first question, the patients' general understanding about X-rays was that the machine took photographs of inside of the body using rays which cannot be seen with naked eye. X-rays were done to show broken bones. The general opinion about X-rays was that they are beneficial and wonderful. One patient said that, "I would not have lived without them." Eleven out of 50 patients knew the harmful side effects of X-rays as well, but these patients also knew that they are dangerous only in large amounts.

Regarding the second and third questions, only three out of 50 patients knew beforehand that they would have X-rays during their operation. One of them was told in the operation theatre by the anesthetist and radiographer. In the rest of the cases, patients were surprised to know that they were $\mathrm{X}$-rayed during the procedure.

None of the fifty patients were given information regarding protective clothing (lead apron, etc), which can be used during operation. Only one patient knew, but he knew about it before coming to hospital.

Three female patients did not think that X-rays could be of any harm to the fetus during pregnancy. Nine patients (five male and four female) were not sure about any harmful effect of X-rays during pregnancy. Another nine patients (five female and three male) were not sure about the significance of a pregnancy test in trauma victims of reproductive age.

Five females out of these 50 patients were of reproductive age (15-50 yrs), and they knew about their pregnancy state beforehand.

1. What do you understand by "X-rays" and what is your general idea about radiation? (3-7 lines)

2. Do you know that the procedure you had involved X-rays? $\mathrm{Y} / \mathrm{N}$

3. Were you informed about it? $\mathrm{Y} / \mathrm{N}$

4. Were you told about wearing protective clothing from radiation? $\mathrm{Y} / \mathrm{N}$

5. Do you think that radiation can be harmful to pregnant patients? $\mathrm{Y} / \mathrm{N}$

6. Do you think that every woman of child-bearing age should have a pregnancy test before undergoing such surgery? $\mathrm{Y} / \mathrm{N}$

\section{For female patients only (of reproductive age)}

Before coming to hospital, did you already know about your pregnancy status?

i. $Y / N$

If NO, did you have a pregnancy test done before operation (in the hospital)?

$$
\text { ii. } Y / N
$$

Figure I Patient questionnaire. 
One patient, a 46-year-old gentleman, had better understanding than the rest of the group. He enumerated the indication of use of X-rays: ie, fractures, fluid on the lung, cracked ribs, etc. This knowledgeable patient also suffered from congenital anomaly because his mother had had an $\mathrm{X}$-ray while he was in uterus.

\section{Discussion}

The law in England states that, "Before you examine, treat or care for competent adult patients you must obtain their consent." ${ }^{\prime 3}$ The consent should be informed: "Patients need sufficient information before they can decide whether to give their consent: for example information about the benefits and risks of the proposed treatment, and alternative treatments. If the patient is not offered as much information as they reasonably need to make their decision, and in a form they can understand, their consent may not be valid."”

Another concern is whether to use protective clothing for the patient. There are various studies that have measured the radiation dose to the patients in trauma settings and found it within the safe limits. But still patients should be given information about that and an option to use protective clothing. In a pregnant patient, placing a lead shield over abdomen whenever possible provides additional protection for the fetus. ${ }^{4}$

Another concern was about X-rays and pregnant patients with orthopedic trauma. Trauma affects up to $8 \%$ of pregnancies and is the leading cause of death among pregnant women in the US. ${ }^{4}$ Many studies have been done on this subject. In a review article done in Harborview Injury and Research Centre, guidelines for assessing radiation risk to conceptuses have been formulated. ${ }^{5}$ They say that assessment of fetal radiation risk is a complex process. It may involve knowing patient's pregnancy status, nature of radiation administered: its energy and amount (beam quality), distance between radiation source and conceptus, and body habitus of the mother (obesity leads to more scattered radiation and more scatter results in an increased absorbed dose), numbers of radiation exposure, the precise anteroposterior location of the uterus (a conceptus within an anteverted uterus may receive $150 \%$ greater dose than that if the uterus was in retroverted position). Risk assessment may involve radiation physicists and a safety officer to estimate absorbed dose to the conceptus by applying sophisticated methods. Nevertheless, a simple qualitative dose assessment can provide a crude estimate of the risk and appropriate triage to more formal quantitative assessment. This assessment categorizes exposures in three broad categories (Table 1). As a crude estimation of absorbed dose to the conceptus, the authors used an estimator in which dose can be estimated at 2, 5, and $10 \mathrm{mGy}$ (Table 2).
Table I Qualitative radiation risk categories ${ }^{5}$

\begin{tabular}{ll}
\hline Risk category & Dose range (mGy) \\
\hline Low & $<10$ \\
Intermediate & $10-50$ \\
High & $>250$ \\
\hline
\end{tabular}

On the basis of this crude assessment, if the estimated dose is "low," the doctors will reassure the patient and her family that there is an almost negligible risk of injury to the conceptus. If exposure is greater than $10 \mathrm{mGy}$ (intermediate and high risk category), then it is better to obtain accurate dose estimates by contacting radiation safety personnel and informing patients clearly of the risk.

Mann and colleagues ${ }^{5}$ emphasize the fact that trauma surgeons must balance the risks and benefits of diagnostic radiographic procedure on potentially pregnant patients and should know the range and likelihood of effects that radiation might have on pregnancy. This quantitative and qualitative assessment is helpful for the pregnant patient before she can decide before consent and will also allay her anxiety about radiation exposure to conceptus. Such an estimate may prove beneficial in establishing risk-benefit ratios for physicians, may help in counseling patients, and may serve as a baseline for further studies regarding radiation exposure. ${ }^{6}$

Most of what is known about the effects of ionizing radiation in humans has come from studies of pregnant women who were irradiated by the explosive effects of the atomic bomb in Nagasaki and Hiroshima, Japan. ${ }^{7,8}$ The potential effects of radiation to the fetus may be grouped into three categories: teratogenesis (fetal malformation), carcinogenesis (induced malignancy), and mutagenesis (alteration of germ-line genes). ${ }^{5}$

The maximum recommended dose by the US National Council on radiation protection during pregnancy is $50 \mathrm{mGy}$ (5 rad). ${ }^{5}$ The policy of the American College of Obstetricians and Gynaecologists (ACOG) states that exposure to less than 5 rads has not been associated with an increase in fetal anomalies or pregnancy loss. ${ }^{9}$ Table 3 shows the fetal radiation exposure (approximate) during common radiographic studies. ${ }^{6}$

Table 2 Conceptus dose estimation based on type of medical $\mathrm{X}$-ray source when conceptus in irradiated volume ${ }^{5}$

\begin{tabular}{ll}
\hline Diagnostic X-ray procedure & Estimated dose range \\
\hline $\begin{array}{l}\text { Conventional radiograph } \\
\text { (eg, X-ray of pelvis) }\end{array}$ & $2 \mathrm{mGy} /$ exposure \\
CT (eg, CT of abdomen) & $5 \mathrm{mGy} / \mathrm{slice}$ \\
Fluoroscopy (eg, pelvic angiography) & $10 \mathrm{mGy} /$ minute \\
\hline
\end{tabular}

Abbreviation: $\mathrm{CT}$, computed tomography 
Table 3 Fetal radiation exposure (approximate) during common radiographic studies ${ }^{4}$

\begin{tabular}{lll}
\hline Radiographic study & Rad & $\begin{array}{l}\text { No of studies to reach } \\
\text { Cumulative 5 rad }\end{array}$ \\
\hline Cervical spine & 0.002 & 2,500 \\
Chest (two views) & 0.00007 & 71,429 \\
Pelvis & 0.040 & 125 \\
Hip (single view) & 0.213 & 23 \\
CT head (I0 slices) & $<0.050$ & $>100$ \\
CT chest (I0 slices) & $<0.100$ & $>50$ \\
CT abdomen (I0 slices) & 2.600 & $\mathrm{I}$ \\
CT lumbar spine (5 slices) & 3.500 & $\mathrm{I}$ \\
Ventilation-perfusion scan & 0.215 & 23 \\
\hline
\end{tabular}

Abbreviation: CT, computed tomography.

Another issue is of pregnancy test in trauma patients. Trauma is the leading cause of death amongst pregnant patients in US, ${ }^{5}$ with the rates of fetal mortality as high as $60 \%{ }^{10}$ A study in US (R Adams Cowley Shock Trauma center) showed that, out of all the women of reproductive age admitted in the trauma center (during their study period), $11.4 \%$ were found to be pregnant incidentally (pregnancy status unknown to the trauma team). ${ }^{11}$ Fetal mortality in this group was significantly higher (77\%). On the basis of that, they concluded that pregnancy test should be considered in all female trauma victims of childbearing age. ${ }^{11}$

\section{Conclusions}

While consenting to orthopedic trauma surgery, the patient should be informed about use of X-rays intraoperatively and their fears be allayed. We agree that physicians should be explaining to the patients about the benefits and risks of the treatment. Our study does not emphasize that patient should make the decisions on their own. We emphasize that patients be informed about the treatment given to them.

In female trauma victims of child-bearing age, a pregnancy test should be considered mandatory. Female trauma victims of child-bearing age should be informed about radiation exposure and the risks involved.

\section{Disclosure}

The authors report no conflicts of interest in this work.

\section{References}

1. Treacy A, Mahony R, Teehan M, Alarab M, Syed A, Geary M. Understanding operative intervention in childbirth: a patient perspective. J Obstet Gynaecol. 2006;26:752-754.

2. Mittal R, Morley J, Dinopoulos H, Drakoulakis E, Vermani E, Giannoudis P. Use of bio-resorbable implants for stabilisation of distal radius fractures: the United Kingdom patient's perspective. Injury. 2005;36:333-338.

3. Department of Health. 12 key points on consent: the law in England. 2002. [Cited Oct 27, 2008]. Available from: http://www. dh.gov.uk/en/Publicationsandstatistics/Publications/Publications PolicyAndGuidance/DH_4006131.

4. Flik K, Kloen P, Toro JB, Urmey W, Nijhuis JG, Helfet DL. Orthopaedic trauma in the pregnant patient. J Am Acad Orthop Surg. 2006; 14:175-182.

5. Mann FA, Nathens A, Langer S, Goldman SM, Blackmore CC. Communicating with the family: the risks of medical radiation to conceptuses in victims of major blunt-force torso trauma. J Trauma. 2000;48:354-357.

6. Kim PK, Zhu X, Houseknecht E, Nickolaus D, Mahboubi S, Nance ML. Effective radiation dose from radiologic studies in paediatric trauma patients. World J Surg. 2005;29:1557-1562.

7. Blot WJ, Miller RW. Mental retardation following in utero exposure to the atomic bombs of Hiroshima and Nagasaki. Radiology. 1973;106:617-619.

8. Yamazaki JN, Schull WJ, Perinatal loss and neurologic abnormalities among children of the atomic bomb: Nagasaki and Hiroshima revisited 1949-1989. JAMA. 1990;264:605-609.

9. Guidelines for diagnostic imaging during pregnancy. The American College of Obstetricians and Gynecologists. Int J Gynaecol Obstet. 1995;51:288-291.

10. Esposito TJ. Trauma during pregnancy. Emerg Med Cin North Am. 1994;12:167-199.

11. Bochicchio GV, Napolitano LM, Haan J, Champion H, Scalea T. Incidental pregnancy in trauma patient. J Am Coll Surg. 2001;83:815-818.

\section{Publish your work in this journal}

Drug, Healthcare and Patient Safety is an international, peer-reviewed open-access journal exploring patient safety issues in the healthcare continuum from diagnostic and screening interventions through to treatment, drug therapy and surgery. The journal is characterized by the rapid reporting of reviews, original research, clinical, epidemiological and post-marketing surveillance studies, risk management, health literacy and educational programs across all areas of healthcare delivery. The manuscript management system is completely online and includes a very quick and fair peer-review system. Visit http://www.dovepress.com/ testimonials.php to read real quotes from published authors. 